\title{
EFEITO DA TEMPERATURA DE SECAGEM NAS PROPRIEDADES FÍSICAS E MECÂNICAS DA MADEIRA: UMA REVISÃO
}

\section{Roberta Rodrigues Roubuste ${ }^{1}$; Nadia Helena Bianchini ${ }^{2}$; Guilherme Valcorte ${ }^{3}$; Luciane Gorski ${ }^{4}$; Kássya Melissa Oliveira de Souza ${ }^{5}$; Maiara Talgatti ${ }^{6}$; Laura Hoffmann de Oliveira7; Clovis Roberto Haselein ${ }^{8}$}

\section{RESUMO}

A secagem da madeira consiste em uma etapa de grande importância durante o processamento, pois, quando realizada de forma satisfatória, possibilita 0 melhoramento de suas propriedades. Nesse sentido, o objetivo do presente trabalho é abordar o efeito da temperatura de secagem baixa, convencional e alta nas propriedades físicas e mecânicas da madeira. O respectivo trabalho foi elaborado a partir de uma revisão da literatura, na qual se realizou consulta em livros, revistas e periódicos on-line. $O$ processo de secagem da madeira em altas temperaturas acarreta na diminuição da resistência da madeira, em razão da dilatação e da movimentação térmica das moléculas de seus componentes. A secagem da madeira proporciona a redução do teor de umidade variando conforme a utilização final do produto, com redução na movimentação dimensional das peças, inibição contra agentes deterioradores e também aumento das propriedades da madeira.

Palavras-chave: Resistência da madeira; Qualidade da madeira; Teor de umidade.

Eixo Temático: Sociedade e Ambiente (SA).

\section{INTRODUÇÃO}

A madeira caracteriza-se como um material heterogênico, poroso, higroscópico e anisotrópico (ALMEIDA et al., 2016). Conforme Gallio et al. (2018),

\footnotetext{
${ }^{1}$ Mestranda pelo Programa de Pós-Graduação em Engenharia Florestal-UFSM. robertaroubuste@hotmail.com

${ }^{2}$ Doutoranda pelo Programa de Pós-Graduação em Engenharia Florestal-UFSM. nhbianchini@gmail.com

${ }^{3}$ Doutorando pelo Programa de Pós-Graduação em Engenharia Florestal-UFSM. gvalcorte@gmail.com

${ }^{4}$ Engenheira Florestal, Dra. lu_gorski@hotmail.com

${ }^{5}$ Doutoranda pelo Programa de Pós-Graduação em Biodiversidade e Evolução-Museu Paraense Emílio Goeldi. engkassya@gmail.com

${ }^{6}$ Engenheira Florestal, Dra. maiara.talgatti@hotmail.com

${ }^{7}$ Doutoranda pelo Programa de Pós-Graduação em Engenharia Florestal-UFPR. laurahoff@hotmail.com

${ }^{8}$ Orientador. Professor Titular do Departamento de Ciências Florestais-UFSM. clovis.haselein@gmail.com
} 
EDUCACÃO, SAÚDE

ETECNOLOGIA

26 A 28 DE OUTUBRO DE 2021

essas especificidades propiciam uma maior qualidade a madeira, possibilitando que sejam empregadas na produção de produtos de origem madeireira.

O aprofundamento do estudo sobre a madeira é de extrema importância, uma vez que o entendimento a respeito dos processos de industrialização deste material possui grande relevância para a melhoria do seu uso e aproveitamento. Nesse sentido, como parte deste conhecimento destaca-se o processo de secagem da madeira, que corresponde na redução da umidade da madeira até um teor de umidade definido (GUELLA, 2016).

A secagem da madeira consiste em uma etapa de grande importância durante o processamento, pois, quando realizada de forma satisfatória, possibilita o melhoramento das propriedades da madeira, assegurando não somente a qualidade da matéria-prima, como também a do produto final (MARQUES et al., 2006). Segundo os mesmos autores, a madeira quando seca até o teor de umidade final adequado, já ocorreu a maior parte da contração, fazendo com que o material tornase menos susceptível a movimentos dimensionais e, como consequência, mais estável.

Conforme Klitzke (2007), as características de maior importância relacionadas à espécie são anatomia, densidade e anisotropia de contração e inchamento. O estudo a respeito das propriedades tecnológicas da madeira a ser seca é de grande relevância quando o planejamento é desenvolver programas de secagem.

Nesse sentido, o processo de secagem minimiza a tendência da madeira apresentar empenos, rachaduras e também aparecimento de organismos xilófagos. A secagem da madeira proporciona melhoria das propriedades mecânicas como a flexão estática, compressão, dureza e também o cisalhamento, assim como das propriedades de isolamento elétrico e acústico (MARTINS, 1988).

Em relação à temperatura durante a secagem de madeira, a mesma desempenha influência direta na velocidade de secagem, pois, quanto maior a temperatura, maior será a taxa de evaporação de umidade da madeira e também em relação à umidade relativa do ar no interior da estufa (SEVERO, 1989; KLITZKE, 2002). Contudo, a temperatura caracteriza-se como uma grandeza física utilizada para a determinação do grau de agitação ou a energia cinética das moléculas de 
uma determinada quantidade de matéria. Esta energia é viabilizada na forma de calor, correspondendo à energia em movimento que se transfere de um corpo ao outro pela diferença de temperatura (INCROPERA et al., 2008).

Sendo assim, o objetivo do presente trabalho é abordar o efeito da temperatura de secagem baixa, convencional e alta nas propriedades físicas e mecânicas da madeira.

\section{METODOLOGIA}

O respectivo trabalho foi elaborado a partir de uma revisão da literatura, na qual se realizou consulta em livros, revistas e periódicos on-line, por meio da plataforma Google Acadêmico e Periódicos CAPES. As palavras-chave utilizadas para a pesquisa foram: "secagem da madeira", "temperatura e secagem da madeira" e "propriedades físicas e mecânicas da madeira". Posteriormente, realizou-se a extração das informações de relevância para a redação do manuscrito.

\section{RESULTADOS E DISCUSSÕES}

\subsection{TEMPERATURA DE SECAGEM DA MADEIRA}

\subsubsection{Baixa Temperatura}

A secagem da madeira a baixa temperatura é realizada com temperaturas inferiores a $50{ }^{\circ} \mathrm{C}$, em que a circulação do ar pode ser natural ou forçada. Esse tipo de secagem pode ser por desumidificação, secagem solar e também por présecadores.

Quanto aos desumidificadores, os mesmos são compostos de um compressor, válvula de descompressão, dois trocadores de calor, dutos e ventiladores, em que as variáveis de controle deste processo são a umidade relativa e a temperatura, e os equipamentos atingem temperaturas em torno de $50{ }^{\circ} \mathrm{C}$ (JANKIWSKY, 1995; KIENE, 1997).

$\mathrm{Na}$ secagem por meio da desumidificação, inicialmente o ar que circula no interior da câmara passa por serpentinas frias, em que se perde uma grande quantidade de umidade, pela fase da condensação. A água então é formada e drenada para o exterior, o ar passa por trocadores de calor para seu aquecimento e, após isso, lançado para o interior da câmara por ventiladores. Após passar pelas 
pilhas de madeira e adquirir a umidade, o ar passa por um sistema de desumidificação, com recomeço do processo (KIENE, 1997; SANTINI, 1996).

O processo de secagem por desumidificação com temperaturas entre $40^{\circ} \mathrm{C}$ a $50{ }^{\circ} \mathrm{C}$ é considerada lenta em comparação com a secagem convencional. Contudo, as estufas com desumidificador possuem custo de instalação relativamente menor e são mais simples de serem operadas (MENDES, 1998).

A secagem por desumidificação possibilita menor incidência de defeitos provocados pela secagem na madeira, sendo indicado para madeiras de secagem lenta, propiciando materiais com qualidade (MARTINS, 1988). A desvantagem está relacionada com a grande demanda de consumo de energia elétrica para secagem de madeiras com teor de umidade abaixo de $20 \%$.

A secagem solar geralmente possui paredes e/ou tetos transparentes, para permitir a passagem da energia solar para o seu interior (SHARMA, 1975). Essa energia atinge uma superfície plana pintada de preto, que funciona como um coletor, localizada entre o teto e a pilha de madeira, sendo transformada em calor, o qual é refletido pelas superfícies transparentes e capturado pela estufa (MARTINS, 1988).

Os ventiladores fazem a circulação do ar no interior dessa estufa, fazendo o processo de secagem (VITAL; COLLON, 1974). Quanto ás vantagens deste processo, as estufas são construídas com boa qualidade, custo relativamente menor e construções mais simples. Porém, as desvantagens estão relacionadas quanto a dependência do clima e também em razão do tamanho destas estufas, que podem variar entre $1 \mathrm{~m}^{3}$ a $22 \mathrm{~m}^{3}$, mas a maioria apresenta de $2 \mathrm{~m}^{3}$ a $5 \mathrm{~m}^{3}$.

Os pré-secadores possuem como finalidade a redução do tempo de secagem e defeitos na madeira. A pré-secagem é realizada com baixas temperaturas em estufas de grandes dimensões e adição de calor e circulação forçada de ar, sendo feita a secagem de madeira verde até atingir um teor de umidade em torno de $25 \%$ (MARTINS, 1988).

Podem ter capacidade de 100 a $2000 \mathrm{~m}^{3}$ com temperatura de operação entre $27^{\circ} \mathrm{C}$ a $40^{\circ} \mathrm{C}$, sendo que as condições internas são mantidas constantes, com umidade relativa de variação entre $50 \%$ a $80 \%$ e velocidade de circulação do ar entre 0,4 a 0,8 m/s (PONCE; WATAI, 1985). 
A principal vantagem da secagem realizada por pré-secadores está relacionada na possibilidade de aplicar à madeira as condições ideais da secagem ao ar livre, fazendo com que as peças mantenham-se protegidas das modificações que ocorrem em ambiente natural (MENDES, 1996). São utilizados para espécies de secagem lenta, proporcionando uma pré-secagem mais rápida e com menor incidência de defeitos. Os pré-secadores contribuem na facilitação da secagem convencional até o teor de umidade final pretendido, propiciando o aumento da produtividade da estufa e redução dos custos da secagem (MENDES, 1996).

\subsubsection{Secagem Convencional}

A secagem convencional é processo de maior versatilidade para o controle das varáveis da secagem (ALMEIDA, 2011). Conforme Jankowsky (1995), os secadores convencionais constituem de um sistema de aquecimento, de umidificação do ar e um sistema de circulação do ar, os quais operam com temperaturas entre $50^{\circ} \mathrm{C}$ a $90^{\circ} \mathrm{C}$.

O funcionamento da secagem convencional é por meio de ventiladores que empurram o ar para os trocadores de calor, por meio de radiadores ou serpentinas (SANTINI, 1996). Após isso, o ar alcança a pilha de madeira de forma transversal, ressaltando que o os ventiladores devem distribuir uniformemente o ar na estufa, geralmente com velocidade entre $2-3 \mathrm{~m} / \mathrm{s}$ e a umidade relativa é contida por sistema de vaporizadores de água e sistemas de renovação do ar (SANTINI, 1996).

De acordo com Jankowsky (2000), os secadores convencionais devem possuir bom isolante térmico para minimizar problemas com perdas de calor por radiação e consumo de vapor; a circulação do ar deve ser distribuída de forma uniforme e também ressalta-se que seja feito um bom dimensionamento das janelas e ventiladores. Conforme o mesmo autor, secagem em altas temperaturas podem propiciar rachaduras e trincas nas peças de madeira, contudo, após a remoção da água de capilaridade, em torno de $28 \%$ do ponto de saturação das fibras (PSF), a temperatura de secagem pode ser maior. 


\subsubsection{Secagem a alta temperatura}

O processo de secagem em alta temperatura é semelhante à secagem convencional, porém com temperatura entre $100{ }^{\circ} \mathrm{C}$ a $130{ }^{\circ} \mathrm{C}$ (KIENE, 1997). As principais diferenças da secagem a alta temperatura em relação à secagem convencional estão relacionadas com o aumento da velocidade do ar, as condições de ventilação são melhores, assim como o empilhamento e também no sistema de isolamento (TOMASELLI, 1976). Essas diferenças propiciam a redução do tempo de secagem, tornando o processo com maior produtividade e flexibilidade, e também redução no espaço de estocagem das peças.

Quanto às desvantagens da utilização da secagem a alta tempertura, destaca-se o surgimento de defeitos que podem vir a aparecer na madeira. Contudo, em estufas mais modernas, são utilizados planos de controle com rigorosidade nos parâmetros no processo (KIENE, 1997).

\subsection{RELAÇÃO DA TEMPERATURA DE SECAGEM COM AS PROPRIEDADES FÍSICAS E MECÂNICAS DA MADEIRA}

A madeira geralmente está submetida a alterações no teor de umidade em função das circunstâncias do ambiente em que se encontra, ou seja, a peça está quase sempre perdendo ou ganhando umidade para atingir uma condição de equilíbrio com a atmosfera (MORESCHI, 2005). A ocorrência desta característica evidencia que a madeira está em equilíbrio higroscópico com o ambiente.

A temperatura e a umidade relativa do ar destacam-se como os principais fatores que condicionam a umidade de equilíbrio da madeira. Entre a umidade da madeira, umidade relativa do ar e temperatura é estabelecido um equilíbrio higroscópico de grande relevância para a secagem do material, visto que por meio desta relação é possível fazer o controle e regular o processo de secagem (SEVERO et al., 2001).

O aumento da temperatura de secagem proporciona a diminuição da higroscopicidade da madeira. De acordo com Tomaselli (1981), há a diminuição do teor de umidade de equilíbrio com o aumento da temperatura, sobretudo quando considera-se temperaturas acima de $100{ }^{\circ} \mathrm{C}$. Kininmonyh (1976) e Koslik (1973) salientam que esta redução da higroscopicidade do material depende não somente 
da temperatura, como também do tempo em que a madeira é exposta ao tratamento.

O processo de secagem da madeira em altas temperaturas acarreta na diminuição da resistência da madeira, em razão da dilatação e da movimentação térmica das moléculas de seus componentes (MORESCHI, 2005). Segundo o mesmo autor, temperaturas acima de $100{ }^{\circ} \mathrm{C}$ podem ocasionar a degradação térmica da madeira.

Em um estudo realizado por Calvert (1965), a respeito do efeito da alta temperatura de secagem em espécies do Canadá, encontrou resultados de redução a respeito da umidade de equilíbrio da madeira, entre 1-2\%. De acordo com Stamm (1964), a diminuição da higroscopicidade da madeira está relacionada com pequenas modificações químicas, principalmente em relação à degradação parcial das hemiceluloses. As hemiceluloses, que são substâncias componentes da madeira, demonstram ser menos estáveis, e, portanto, podem ser de fácil degradação.

A temperatura e velocidade de secagem possuem uma relação diretamente proporcional, que quanto maior a temperatura maior será a velocidade de secagem (SEVERO, 2007). Segundo o mesmo autor, a secagem da água higroscópica é influenciada diretamente pela temperatura, em que maiores temperaturas poderão provocar alteração na umidade relativa do ar acelerando o processo de difusão, 0 qual é responsável pelo aumento da taxa de secagem (SEVERO, 2007). Ressalta-se que o aumento não programado da temperatura pode ocasionar no surgimento de defeitos irreversíveis na madeira em processo de secagem.

Em relação à massa específica, madeiras menos densas e que possuem maior espaço nas cavidades celulares, o processo de secagem será mais acelerado (BROWN et al., 1952). Portanto, é fundamental o cuidado com a temperatura de secagem a ser aplicada, levando sempre em consideração a densidade de cada material.

De acordo com Hart (1965), há o aumento do tempo de secagem de acordo com o teor de umidade presente na madeira, tanto para madeiras com elevada permeabilidade, onde o fluxo de massa e a remoção da umidade superficial é o fator 
EDUCAÇÃO, SAÚDE

ETECNOLOGIA

26 A 28 DE OUTUBRO DE 2021

limitante, como também para madeiras impermeáveis em que a difusão é o fator de controle. O tempo de secagem de duas peças de madeira, por exemplo, são diferentes até atingir o PSF, entretanto, quando os materiais atingem o mesmo ponto, as mesmas necessitam do mesmo tempo para secagem.

Quanto à retratibilidade da madeira, que é definida como a variação dimensional da madeira, em função da troca de umidade da peça com o meio que a envolve, até que se atinja uma condição de equilíbrio, ou seja, equilíbrio higroscópico (REVISTA DA MADEIRA, 2001).

O aumento da temperatura acarreta na contração da madeira, fator que está relacionado principalmente à presença do colapso da parede celular, em razão das forças capilares que excedem a resistência à compressão da madeira no sentido perpendicular às fibras (REVISTA DA MADEIRA, 2001).

A temperatura de secagem também influencia nas propriedades mecânicas na madeira, como a flexão estática, módulo de elasticidade e módulo de ruptura (GATTO et al., 2008). Em um estudo realizado por Oliveira e Tomaselli (1981), o aumento da temperatura de secagem de madeira da espécie Araucaria angustifolia em $140{ }^{\circ} \mathrm{C}$ e $180^{\circ} \mathrm{C}$ propiciam a diminuição das variáveis do módulo de elasticidade, módulo de ruptura e tensão no limite de proporcionalidade, em comparação à secagem com temperatura de $20^{\circ} \mathrm{C}$.

Quanto à resistência da madeira à compressão, há uma relação inversamente proporcional, pois o aumento da temperatura ocasiona na diminuição da resistência do material à compressão (MORESCHI, 2005).

\section{CONCLUSÃO}

A secagem da madeira proporciona a redução do teor de umidade variando conforme a utilização final do produto, com redução na movimentação dimensional das peças, inibição contra agentes deterioradores e também aumento das propriedades da madeira. Contudo, é importante salientar que durante todo o processo de secagem sejam utilizadas técnicas que proporcionem a qualidade do material, e de acordo com as características de cada espécie e suas limitações. 


\section{REFERÊNCIAS}

ALMEIDA, B. C. Contribuição para melhoria do processo de secagem convencional de madeiras serradas na região norte do estado de Mato Grosso.

Dissertação (mestrado) Setor de Ciências Agrárias, Universidade Federal do Paraná, Curitiba, 2011.

ALMEIDA, D. H.; FERRO, F. S.; ICIOMOTO, F. H.; TAKESHITA, S.; MODES, K. S.; ALMEIDA, T. H.; CHRISTOFORO, A. L.; LAHR, F. A. R. Determinação da rigidez do Pinus elliotti em diferentes teores de umidade por meio de ensaio mecânicos não destrutivos. Scientia florestalis, Piracicaba, v. 44, n. 110, p. 303-309, 2016.

BATISTA, D. C.; KLITZKE, R. J.; ROCHA, M. P. da. Proposta de programa de secagem para a madeira de "guajará" (Micropholis venulosa Mart. et Eichler) Pierre, Sapotaceae. Ciência da Madeira, v. 3, n. 1, p. 22-32, 2012.

BROWN, H. P.; PANSHIN, A. J.; FORSAITH, C. C. Textbook of wood technology II. the physical, mechanical, and chemical properties of the commercial woods of the United States. New York: McGraw-Hill, 1952 . 783p.

CALVERT, W. W. High-temperature kiln drying of Eastern Canadian species. Can. Wood Prod. Ind, v. 5, n. 7, p. 34-39, 1965.

GALLIO, E.; ZANATTA, P.; RIBES, D. D.; LAZAROTTO, M.; GATTO, D. A.; BELTRAME, R. Fourier transform infrared spectroscopy in treated woods deteriorated by a white rot fungus. Maderas: Ciencia y Tecnologia, v. 20, n. 3, 2018.

GATTO, D. A.; CALEGARI, L.; SANTINI, E. J.; STANGERLIN, D. M.; TREVISAN, R.; OLIVEIRA, L. da. S. Propriedades da madeira de Pinus elliottii Engelm submetida a diferentes temperaturas de secagem. Cerne, v. 14, n. 3, p. 220-226, 2008.

GUELLA, A. F. Madeira: Desafio e Tendências. Revista da Madeira, 2016. HART, C. A. The drying of wood. Extension Report, North Carolina Agric. Ext. Serv., Raleigh, N. C., n. 27, p. 1 -24, 1965. 
INCROPERA, F. P.; DEWITT, D. P.; BERGMAN, T. L.; LAVINE, A. S. Fundamentos de transferência de calor e da massa. Tradução e revisão técnica: Eduardo Mach Queiroz, Fernando Luiz Pellegrini Pessoa. Rio de Janeiro: LTC, 2008. 643 p.

JANKOWSKY, I. P. Equipamentos e processos para a secagem de madeiras. In: SEMINÁRIO INTERNACIONAL DE UTILIZAÇÃO DA MADEIRA DE EUCALIPTO PARA SERRARIA, 1995, São Paulo. Anais... Piracicaba: IPEF, 1995.

\section{JANKOWSKY, I. P. Melhorando a eficiência dos secadores para madeira} serrada. Piracicaba: IPF, Departamento de ciências florestais, ESALQ/USP, 2000. KIENE, S. Avaliação do processo de secagem de madeira em estufa com banho de vapor. Dissertação (Mestrado) - Universidade federal de Santa Catarina, Florianópolis, 1997.

KININMONTH, J. A. Effects of timbers drying temperature on subsequente moisture and dimensional changes, New Zeland J. For. Sci. v. 6, n. 1, p. 101-107, 1976.

KLITZKE, R. J. Uso do inversor de frequência na secagem de madeiras. 2002. 239 p. Tese (Doutorado em Engenharia Florestal), Universidade Federal do Paraná, Curitiba, 2002.

KLITZE, R. J. Secagem da Madeira. In: OLIVEIRA, J. T. da S.; FIEDLER, N. C.; NOGUEIRA, M. Tecnologias Aplicadas ao Setor Madeireiro. Jerônimo Monteiro: Suprema, p. 271-342, 2007.

KOZLIK, C. J. Effect of Kiln conditions on the dimensional stability of Douglas-Firand western Hemlock. For. Prod. J., v. 23, n. 9, p. 85-92, 1973.

MARQUES, M. H. B.; MARTINS, V. A.; SOUZA, M. R. de.; ALVES, M. V. da. S. Efeito da secagem nas propriedades acústicas da madeira de marupá (Simarouba amara Aubl.). Floresta e Ambiente, v. 12, n. 2, p. 57-64, 2006.

MARTINS, V. A. Secagem de madeira serrada. Brasília: IBDF/DPq/LPF, 1988. 56p. 
MENDES, A. de S. A secagem da madeira. Manaus: INPA, 1996. 64 p. il.

MENDES, A. de S.; MARTINS, V. A.; MARQUES, M. H. B. Programas de secagem para madeiras brasileiras. Brasília: IBAMA, 1998. 114p.

MORESCHI, J. C. Propriedades da Madeira. Curitiba, Paraná, 2005. 194p.

OLIVEIRA, V. S. de.; TOMASELLI, I. Efeito da secagem a altas temperaturas em algumas propriedades físicas e mecânicas de madeira jovem de Araucaria angustifólia (Bert.) O. Ktze. 1981. Disponível em:

<https://revistas.ufpr.br/floresta/article/view/6276/4490>. Acesso em: 18 set. 2021. PONCE, R. M.; WATAI, L. T. Manual de secagem da madeira. Brasília: MIC/STI; São Paulo: IPT, 1985. 70 p.

REVISTA DA MADEIRA. A retratibilidade da madeira. 2001. Disponível em: < http://www.remade.com.br/br/revistadamadeira_materia.php?num=26\&subject>. Acesso em: 18 set. 2021.

SANTINI, E. J. Alternativas para monitoramento e controle do processo de secagem de madeira serrada em estufa. Tese (doutorado) - Setor de Ciências Agrárias, Universidade Federal do Paraná, Curitiba, 1996.

SEVERO, E. T. D. Efeito da temperatura e da velocidade do ar na secagem de madeira serrada de Pinus ellliottii. 1989. 109 p. Dissertação (Mestrado em Engenharia Florestal), Universidade Federal do Paraná, Curitiba, 1989.

SEVERO, E. T. D.; TOMASELLI, I.; BONDUELI, G. M.; REZENDE, M. A. de. Efeito da vaporização na umidade de equilíbrio e sua implicação nas propriedades mecânicas da madeira de Eucalyptus dunnii Maid. 2001. Disponível em: https://revistas.ufpr.br/floresta/article/view/2333/1950.>. Acesso em: 15 de set. 2021. 
SEVERO, E. T. D. A secagem da madeira de eucalipto e seus desafios. In: OLIVEIRA, J. T. S.; FIEDLER, N. C.; NOGUEIRA, M. (Org.). Tecnologias aplicadas ao setor madeireiro II. Vitória, ES: Aquarius, 2007. p. 185-216.

SHARMA, N. S. Solar timber drying. In: SEMINAR ON INDUSTRIAL APPLICATION OF SOLAR ENERGY. Proceedings. 1975, p. 1-6.

STAMM, A. J. Wood and cellulose science. New York: Ronald Press, 1964. 549 p.

TOMASELLI, I. Secagem a alta temperatura e sua aplicação nas condições brasileiras. Floresta, v. 7, n. 1, p. 50-57, 1976.

TOMASELLI, I. Aspectos físicos de secagem de madeira de Pinus elliottii Engelm. Acima de 100ㄷ. Curitiba, 1981. Tese (Professor Titular), Setor de Ciências Agrárias, Universidade Federal do Paraná, 1981.

VITAL, B. R.; COLLON, J. L. Secador solar para madeira. Viçosa, MG: Imprensa Universitária da Universidade Federal de Viçosa, 1974. 